\title{
Microseismic tools for the analysis of the interaction between open pit and underground developments
}

\author{
J.M. Reyes-Montes Applied Seismology Consultants, United Kingdom \\ B.L. Sainsbury Itasca Australia Pty Ltd; and The University of New South Wales, Australia \\ W.S. Pettitt Applied Seismology Consultants, United Kingdom
}

M. Pierce Itasca Consulting Group, United States of America

R.P. Young University of Toronto, Canada

\begin{abstract}
The transition from surface to underground mining presents a series of technical and operational challenges, in particular those arising from the interaction between the cave and the overlying pit. Seismic monitoring provides a unique means to obtain near real-time information about the development of the fracturing process induced by the mining operations. This paper presents the analysis of temporal, spatial and source size patterns in the seismicity recorded during undercutting and production at the Palabora Mine leading to slope failure in the open pit above, and relates these results to full-scale analysis of the rock mass behaviour in three-dimensional numerical models. Based on the application of the techniques described herein, it is shown that the back analysis of the seismic data provides a prediction technique that could now be employed during the planning stages of a mining operation. It is hoped that by employing these new techniques it would be possible to incorporate results from predicted fracture network behaviour into engineering designs in similar future mining operations and thus provide a means to predict and mitigate against large scale failure as observed at the Palabora Mine.
\end{abstract}

\section{Introduction}

The Palabora Mine is located in South Africa approximately $560 \mathrm{~km}$ northeast of Johannesburg. Production from the open cut mine commenced in 1956. At the completion of surface mining in 2003, the open pit was approximately $2 \mathrm{~km}$ in diameter and $800 \mathrm{~m}$ deep. Since 2002, mining at Palabora has continued as an underground block cave located at a depth of approximately $400 \mathrm{~m}$ below the base of the open pit (Glazer and Hepworth, 2003, 2006).

During production from the cave in 2003, a large-scale failure occurred in the northern pit slope. This failure has resulted in the dilution of ore reserves and has caused instability in mine infrastructure located on the pit crest. A plan view of the location of the north wall failure is presented in Figure 1 along with a section through the failure area showing the relationship between the mining footprint and the location of the failure - as defined by numerical modelling (Sainsbury et al., 2008). Within the graphic, the mobilised zone has been defined by a simulated displacement greater than, or equal to $2 \mathrm{~m}$. The yield zone has been defined by a location that has lost some or all of its cohesive strength and provides minimal support to the overlying rock mass. A detailed description of each of these cave behavioural regions is provided in Sainsbury et al. (2008).

A microseismic monitoring system was installed and functional at the mine at the time of the failure. This paper outlines the application of the current seismic prediction techniques developed in conjunction with the Mass Mining Technology (MMT) project that could now be employed during the planning stages of a mining operation. It is hoped that employing these new techniques in the future would allow similar catastrophic failures, such as that experienced at Palabora Mine, to be predicted and mitigated against. 

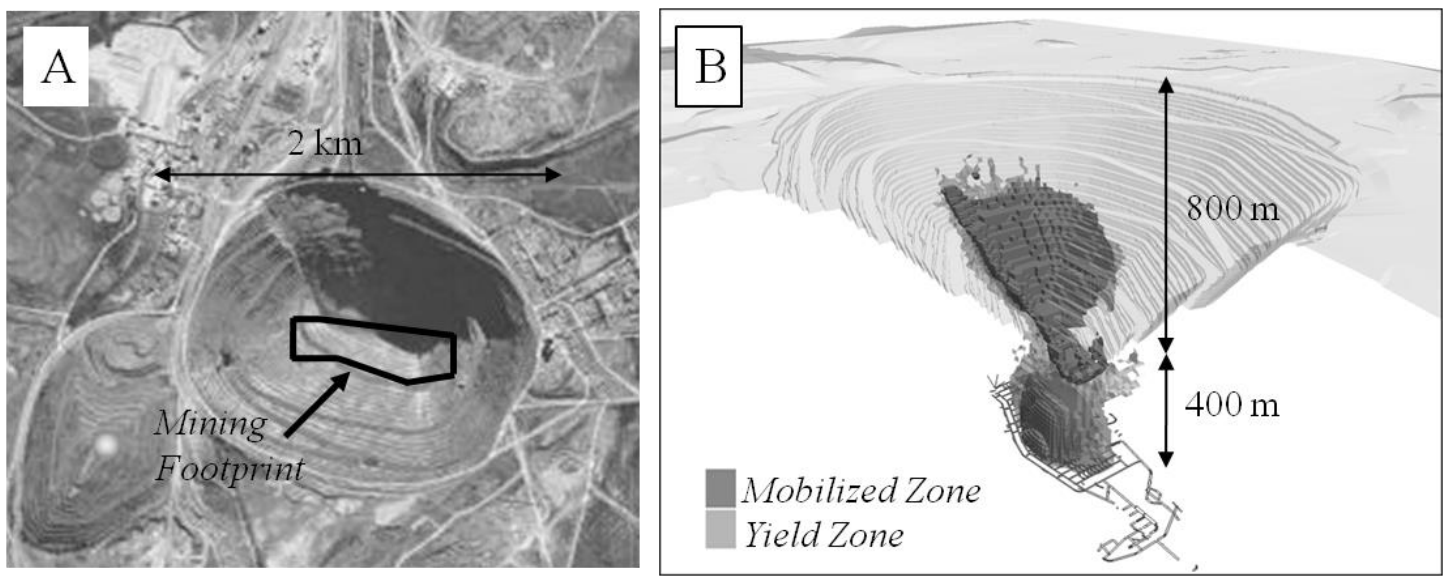

Figure 1 Location and extent of the north wall failure at the Palabora Mine: (a) plan; and (b) section looking northwest

\section{Microseismicity damage quantification methodology}

The stress changes imposed on the rock mass by the different mining operations performed for the exploitation of deep underground caves result in the opening or mobilisation of fractures. The elastic energy radiated from the induced fracturing can be recorded as microseismic events. The location of these microseismic (MS) events provides a unique means to image the position, geometry and nature of the induced or mobilised fracture network (e.g. Young et al., 2007).

Isolated fractures may not significantly affect the integrity of the rock mass and only locally reduce the cohesion of the rock to a point where unstable cracks may develop a critical plane and unstably develop a fracture network. The interaction and coalescence of these isolated fractures marks the onset of damage in the rock and the decrease in the elastic stiffness and cohesive strength of the material leading to failure and mobilisation. Another geotechnical implication of the coalescence of cracks is the creation of paths for the flow of fluids through the rock mass, altering its permeability.

An interpretation of the potential degree of interaction between the induced fractures can be obtained by combining the analysis of spatial and size distribution of the recorded microseismic activity. The cluster index (CI), a damage parameter that combines source location and effective event size provides a means to characterise the degree of clustering and interaction between the fractures acting as sources of microseismic events. This parameter has been applied in the case of hydraulically stimulated fracturing to filter out isolated events and interpret the potential for induction of connected paths for fluids (Reyes-Montes et al., 2009).

The CI was developed for use with MS monitoring to delineate the volume of rock in which significant damage is accumulating and assess the state of the rock mass where instability might occur (Falmagne, 2002). The CI is based on the concepts of critical crack spacing and local crack density presented in Lockner et al. (1992) and Reches and Lockner (1994). It combines source location and effective event size idealising MS events as representing spheres, with radii equal to their calculated source radii, which contain the source crack. This idealisation of the seismic source means that there is an uncertainty in the actual separation of crack tips since it does not take into consideration the direction of the cracks. However, CI is a powerful method for identifying 'potentially' interacting or coalescing cracks. These concepts are presented in Figure 2. Following Reches and Lockner (1994), it can be assumed that the tension induced by a dilating crack decays approximately as the inverse of the distance from the crack and the ratio:

$$
\frac{\mathrm{d}_{\mathrm{ij}}}{\mathrm{L}} \approx 2
$$

where $d_{i j}$ is the distance between cracks and $L$ their length represents the maximum limit for crack interaction, assuming the interaction occurs between two cracks of equal length. 
The cluster index function $\left(\mathrm{CIf}_{\mathrm{ij}}\right)$ for two neighbouring events $\mathrm{i}$ and $\mathrm{j}$ can be defined as:

$$
\mathrm{CIf}_{\mathrm{ij}}=\frac{1}{2}\left[1+\cos \left(\frac{\pi}{2} \frac{\mathrm{d}_{\mathrm{ij}}}{\mathrm{r}_{0 \mathrm{i}}+\mathrm{r}_{0 \mathrm{j}}}\right)\right] \text { and } \mathrm{CIf}_{\mathrm{ij}}=0 \text { for } \frac{\mathrm{d}_{\mathrm{ij}}}{\left(\mathrm{r}_{0 \mathrm{i}}+\mathrm{r}_{0 \mathrm{j}}\right)}>2
$$

where $\mathrm{r}_{0 \mathrm{i}}$ and $\mathrm{r}_{0 \mathrm{j}}$ are the source radii, and $\mathrm{d}_{\mathrm{ij}}$ their separation.

The sum over all the events surrounding the event of interest (i) provides the overall degree of interaction for the source fracture:

$$
\mathrm{CCI}_{\mathrm{i}}=\sum_{\mathrm{j}=1}^{\mathrm{N}} \mathrm{CIf}_{\mathrm{ij}}
$$

where the sum is taken over the total number of neighbouring events $\mathrm{N}$. A value of $\mathrm{cCI}=0$ is interpreted as an isolated event that is essentially out of the stress fields of neighbouring events, and cCI $>0.5$ indicates that the event either has the same source fracture as another event, which can be interpreted as coalesced fractures, or is interacting with several neighbouring events. A value $0<\mathrm{cCI} \leq 0.5$ indicates potential interaction with one or more neighbouring events but no coalescence.

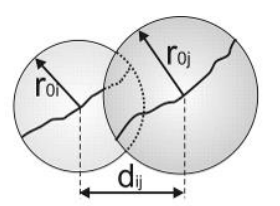

I: Potentially coalesced cracks

$\mathrm{d}_{\mathrm{ij}} \leq \mathrm{r}_{0 \mathrm{i}}+\mathrm{r}_{0 \mathrm{j}}$

CIf $\geq 0.5$

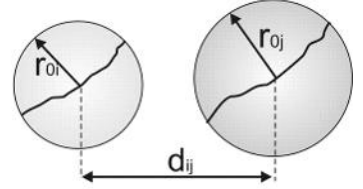

II: Interacting cracks $0<\mathrm{d}_{\mathrm{ij}} \leq 2\left(\mathrm{r}_{0 \mathrm{i}}+\mathrm{r}_{0 \mathrm{j}}\right) \mathrm{d}_{\mathrm{ij}} \geq 2\left(\mathrm{r}_{0 \mathrm{i}}+\mathrm{r}_{0 \mathrm{j}}\right)$ $0<$ CIf $<0.5$

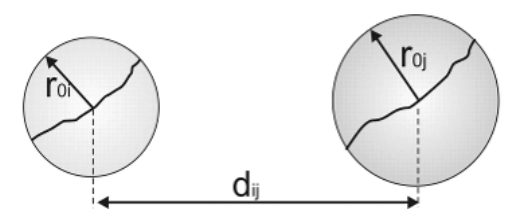

III: Isolated cracks

CIf $=0$

Figure 2 Classification of events according to their cluster index function (CIf). Microseismic sources are represented as spheres containing the fracture

The source radii in this study were calculated from the spectral energy content of the waveform using Madariaga's shear source model (Madariaga, 1976). In this approach, the seismic source is modelled as a circular area with uniform stress release. The typical dimensions of caving projects and the setup of the seismic monitoring array allows to assume far-field conditions, in which case the corner frequency $\left(\mathrm{f}_{0}\right)$ of the theoretical displacement spectra is inversely proportional to the source dimension (Hanks and Wyss, 1972):

$$
f_{0}=\frac{c v_{c}}{r}
$$

where $\mathrm{v}_{\mathrm{c}}$ is the phase velocity and $\mathrm{c}$ is a model dependent constant. In the case of Madariaga's model, the source radius is given by:

$$
\mathrm{r}_{0}=\frac{\mathrm{K}_{\mathrm{c}} \mathrm{v}_{\mathrm{c}}}{2 \pi \mathrm{f}_{0}}
$$

where $\mathrm{K}_{\mathrm{c}}$ is 2.01 for $\mathrm{S}$-waves and 1.32 for P-waves. In this case study, P-wave spectra were used in the calculation of $\mathrm{r}_{0}$.

The evolution of the fracturing process can be quantified by calculating the evolution of the sum of the CI calculated for all located MS events. The CI is also used to identify interacting, clustered, events (events with $\mathrm{CI}>0$ ), and characterise the fracturing process by calculating the ratio of clustered events with respect to the total. This provides a quantification of the degree of interaction between cracks induced or mobilised during the caving process, with high values indicating that induced events locate preferentially in the proximity of previous ones, which corresponds with the growth of connected fractures and potential development of failure planes. 


\section{$3 \quad$ Field data}

\subsection{Palabora Cave development}

Undercutting at the Palabora block cave mine commenced at the end of 2000 and the critical caving hydraulic radius of 45 was reached in April 2002 (Glazer and Hepworth, 2006). Failure of the north slope occurred during 2004, soon after production commenced. Previously numerical simulations were conducted by Sainsbury et al. (2008) to provide an assessment of the failure mechanism associated with the failure. The following section provides an assessment of the development of seismicity around the north wall failure area from a review of the microseismic monitoring data and the consideration of the $\mathrm{CI}$.

\subsection{Caving induced seismicity}

MS activity recorded during the caving of Palabora Mine is strongly dependent on the mining process, with event counts peaking at times when mining operations resume following a stoppage. A total of 97,065 MS events were processed during the study period (Glazer, 2002-2006), with successful picks on at least three stations. Peak daily activity for the period between September 1999 and July 2006 in the recordable range of magnitudes reached approximately 3,700 MS events per month (Figure 3). An upgrade of the seismic array in March 2003 lowered the minimum recordable magnitude threshold from $M_{L}=-1.3$ to $M_{L}=-2.2$. This is reflected in an increased recorded event rate observed from April 2003. Another factor affecting the sensitivity of the microseismic array, and potentially the distribution of located events, is the availability of more stations on the east side of the cave volume, reflected in lower magnitude events located in the east compared with the west.

MS activity initially follows the approximate undercut progression pattern, with a degree of control from local geological intrusive bodies (Figure 4). The initial stages are characterised by clusters of events at two depth levels, above the production level and at a higher level below the open pit (Figure 5). After this initial period, seismicity is more evenly distributed vertically. Towards the end of the monitored period (approximately from November 2005), a significant activity is observed below the production level, eventually becoming the most active sub-volume.

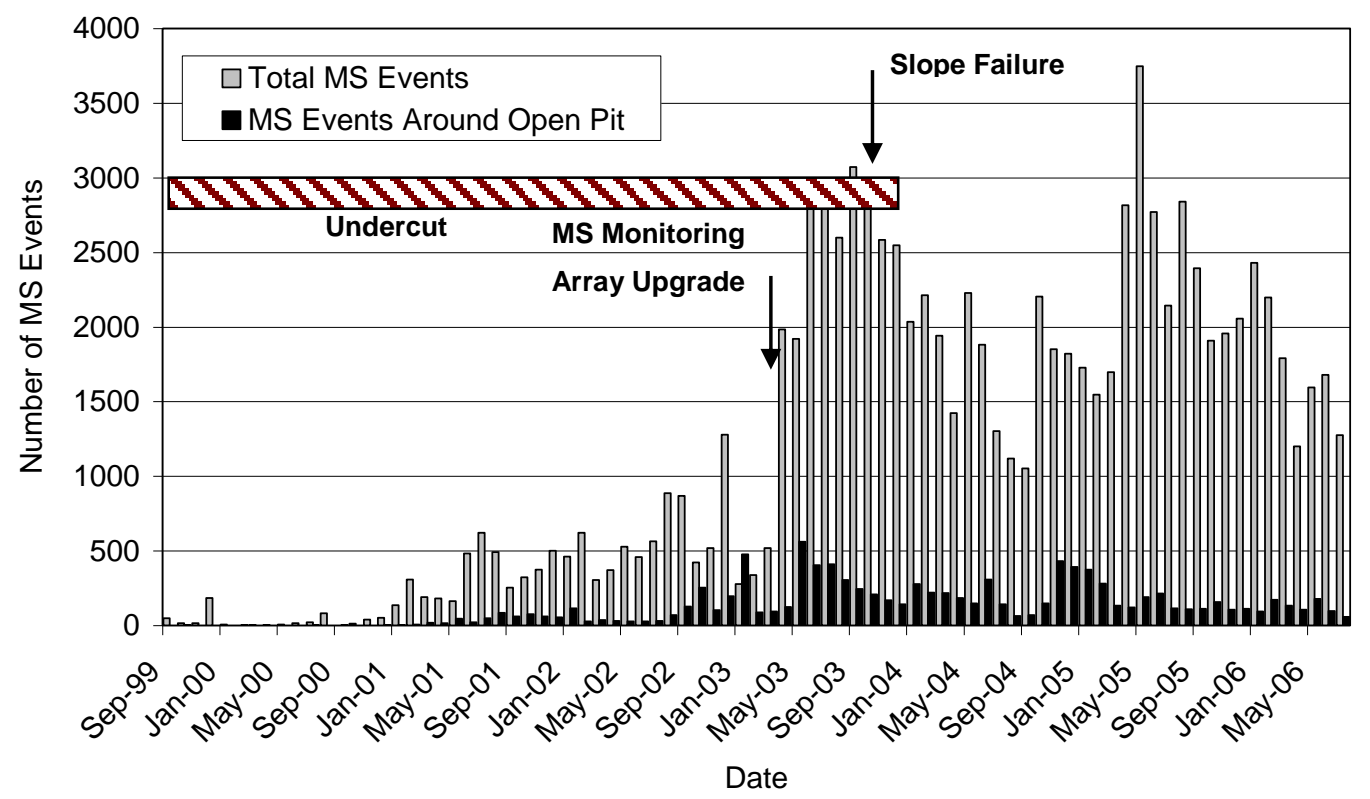

Figure 3 Histogram of monthly rate of recorded events at Palabora Mine between September 1999 and July 2006. The arrows mark the date of the seismic monitoring system upgrade and the north slope failure. The change in sensitivity of the array impacts the number of recorded events and the different analyses presented in this paper 


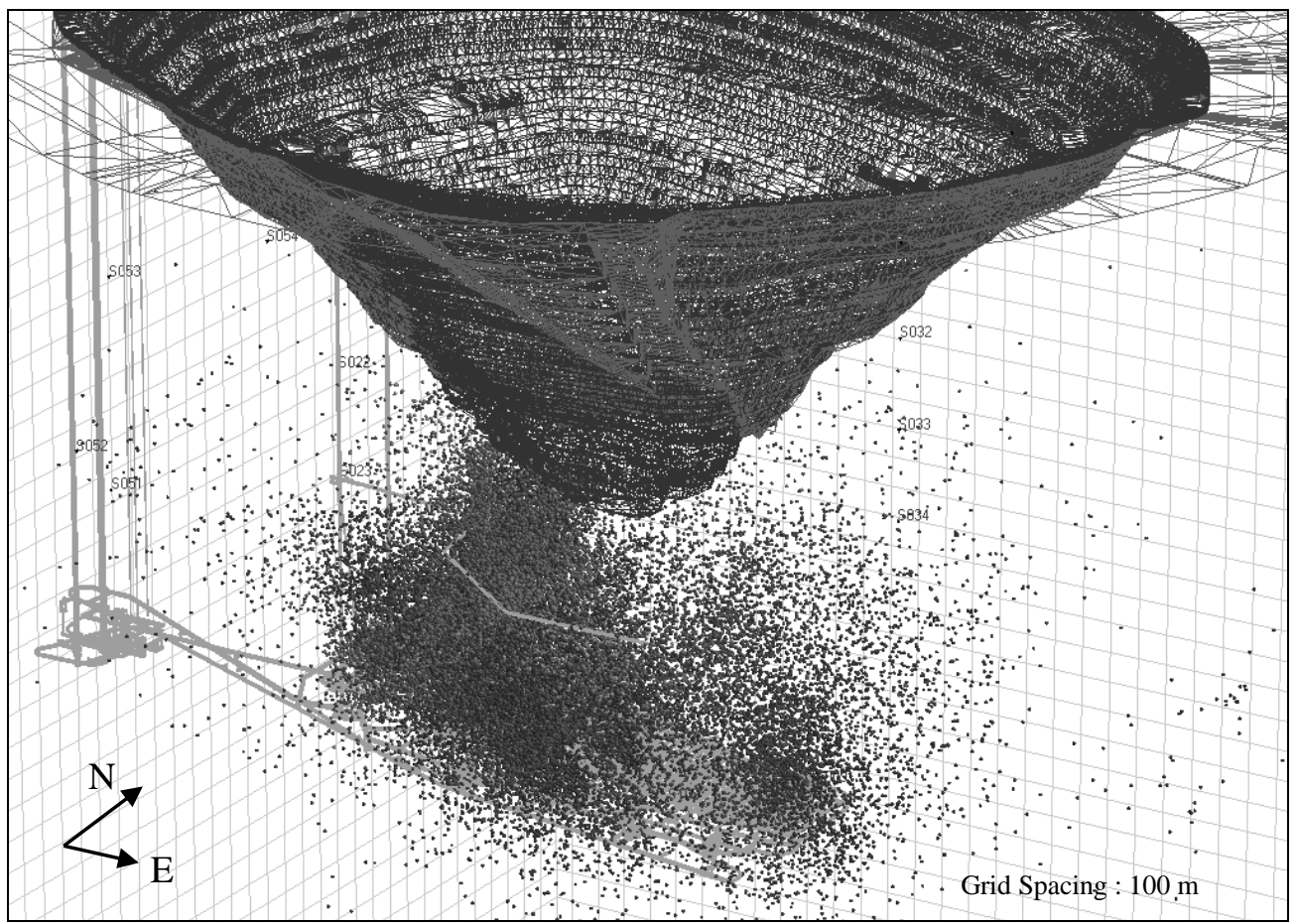

Figure 4 MS events located in the vicinity of the lower open pit looking northwest. The black wireframe shows the outline of the open pit before the failure of the north wall in November 2003, the lighter wireframe corresponds to the outline of the open pit following the north wall failure. Location data provided by Glazer (2002-2006). Visualisation provided by Pettitt and Young (2007)
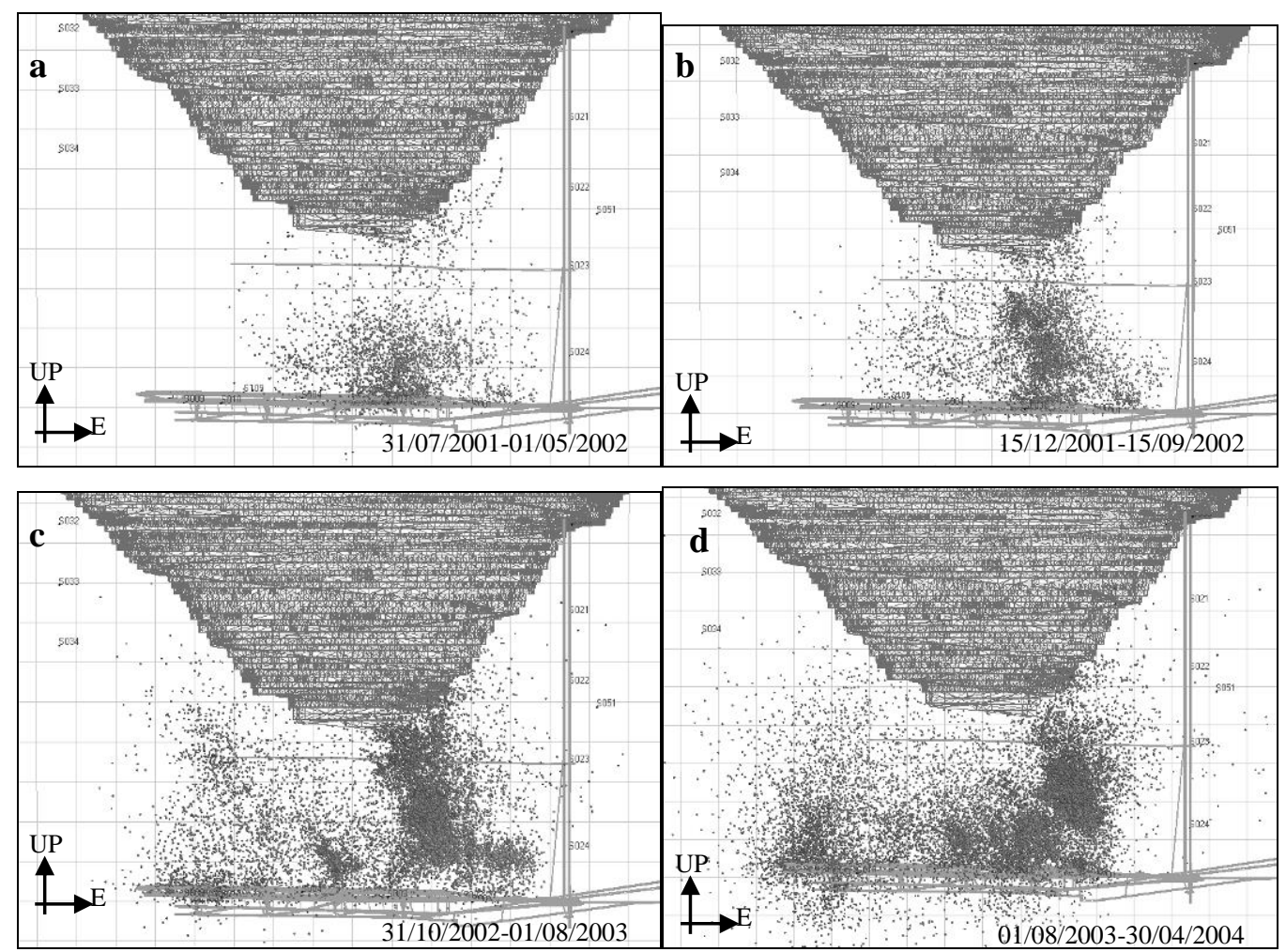

Figure 5 Evolution of the spatial distribution of microseismicity induced by the undercut and production from the underground cave at Palabora Mine 
The ratio of energy contained in the $\mathrm{P}$ - and S-waves is used to interpret the dominant mechanism in the MS events. Following Gibowicz and Kijko (1994) a value of $\mathrm{E}_{\mathrm{S}} / \mathrm{E}_{\mathrm{P}}<10$ is considered indicative of the existence of a significant tensile (volumetric) failure component. Based on this criterion, it was observed that the activity in general show high Es/Ep values, above 10 except for early stages. This indicates that in general the dominant fracturing mechanism induced in the cave volume is shearing (double couple). Considering the different ranges of magnitudes observed in the recorded data, the trends for events with $\mathrm{M}_{\mathrm{w}}<0$ are similar to the trends for the complete population of events, while a relative abundance of a tensile component is found for events with $\mathrm{M}_{\mathrm{w}}>0$, a trend that becomes more obvious for events with $\mathrm{M}_{\mathrm{w}}>0.5$.

\subsection{Evolution of seismic damage}

Approximately 35,000 MS events located in the vicinity of the lower level of the open pit. Upper levels appear inactive, likely due to the geometry of the seismic monitoring array, designed to monitor the underground cave and possible interaction with the lower open pit. The time evolution of this seismicity shows a relatively higher activity in the north side of the volume, with a large fraction of the seismicity concentrating in this region up to four months before the failure of the north slope, followed by a period of more uniformly distributed seismicity. In general, an upwards migration of seismicity is observed associated to the progression of the extraction in the production level of the underground cave (Figure 5). Therefore, the behaviour observed at the lower open pit, can be interpreted as a precursor with respect to the potential seismicity induced at the level of the slope failure.

The distribution of magnitudes of the events located around the lower open pit is analysed by calculating the seismic b-value (Glazer, 2002-2006). The b-value was calculated for a moving window of 100 MS events fitting the distribution of events in the magnitude interval $-0.1<\mathrm{M}_{\mathrm{L}}<0.7$. A minimum in $b$-value is observed before May 2003 (Figure 6), followed by a sharp increase in b-value, in particular between October and November 2003. The analysed volume is positioned approximately $300-400 \mathrm{~m}$ below the area of initiation of the slope failure. This activity occurs before the upward migrating seismic front reaches the region of the slope failure. The activity in the cave volume below the north slope of the open pit volume is sustained over a longer time period, showing a series of minima, with the first one found around the period of the slope failure. A similar pattern is expected to occur for seismic events located at higher levels later in time, however, the existing array was not sensitive enough to locate seismic activity in that region and this hypothesis cannot be confirmed.

In order to evaluate the evolution of damage in Palabora's underground cave, the cluster index was calculated for the complete catalogue of events recorded between September 1999 and July 2006 down to the minimum recorded magnitude of $\mathrm{M}_{\mathrm{L}} \geq-1.5$. The results show high $\mathrm{CI}$ values were around geological discontinuities, in particular around dolerite dykes, and the north wall of the cave in the months preceding the slope failure at the end of November 2003. Figure 7 shows the events in the MS catalogue from Palabora Mine scaled to CI. For clarity, all isolated events $(\mathrm{CI}=0)$ have been filtered out. The high damage indicated by the CI values could be an indication of the loss of cohesion below the north wall that triggered the final failure of this volume of the open pit. It is expected that in the case that seismic data from different areas of the open pit was available, high values of the cluster index would be associated to the development of major structures normally linked to slope failure. 


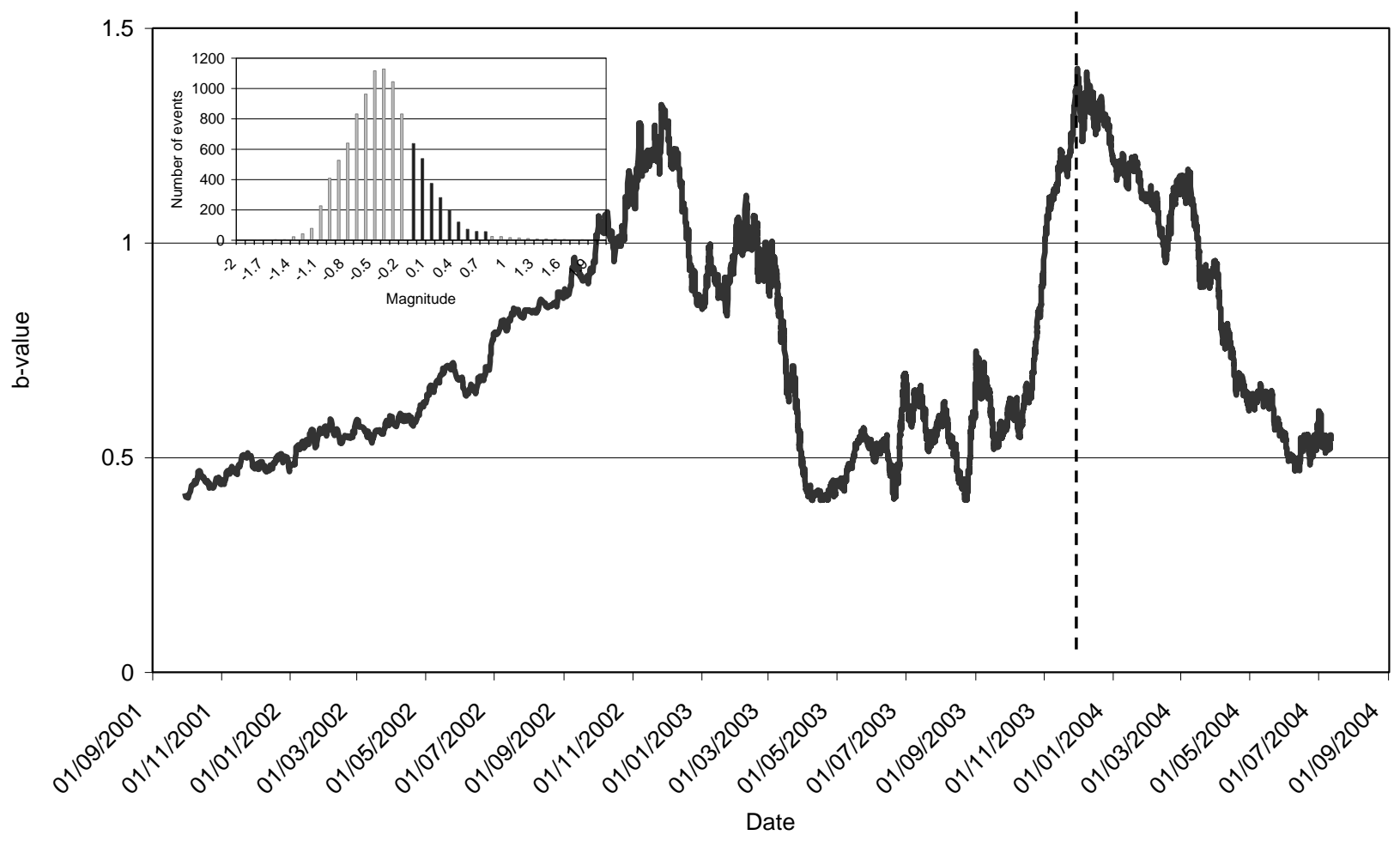

Figure 6 Evolution of the b-value for the events located at the bottom of the open pit of Palabora mine. The vertical dashed line marks the time of the slope failure in the open pit initiated at upper levels. The inset shows the magnitude distribution for the events recorded in the study region, with the key magnitude range used in the calculation of the b-value highlighted

Figure 8 presents the evolution of fracturing in the north side of the cave volume through the fraction of clustered events calculated using the cluster index. The fraction of clustered events is calculated by normalising the number of events with $\mathrm{CI}>0$, indicating interaction, by the total number of events. This parameter varies between 0 and 1 , with 1 corresponding to all events occurring within the interaction distance of one or several neighbours. The curve shows a step increment from July 2003, four months before the failure of the slope above the analysed volume. 

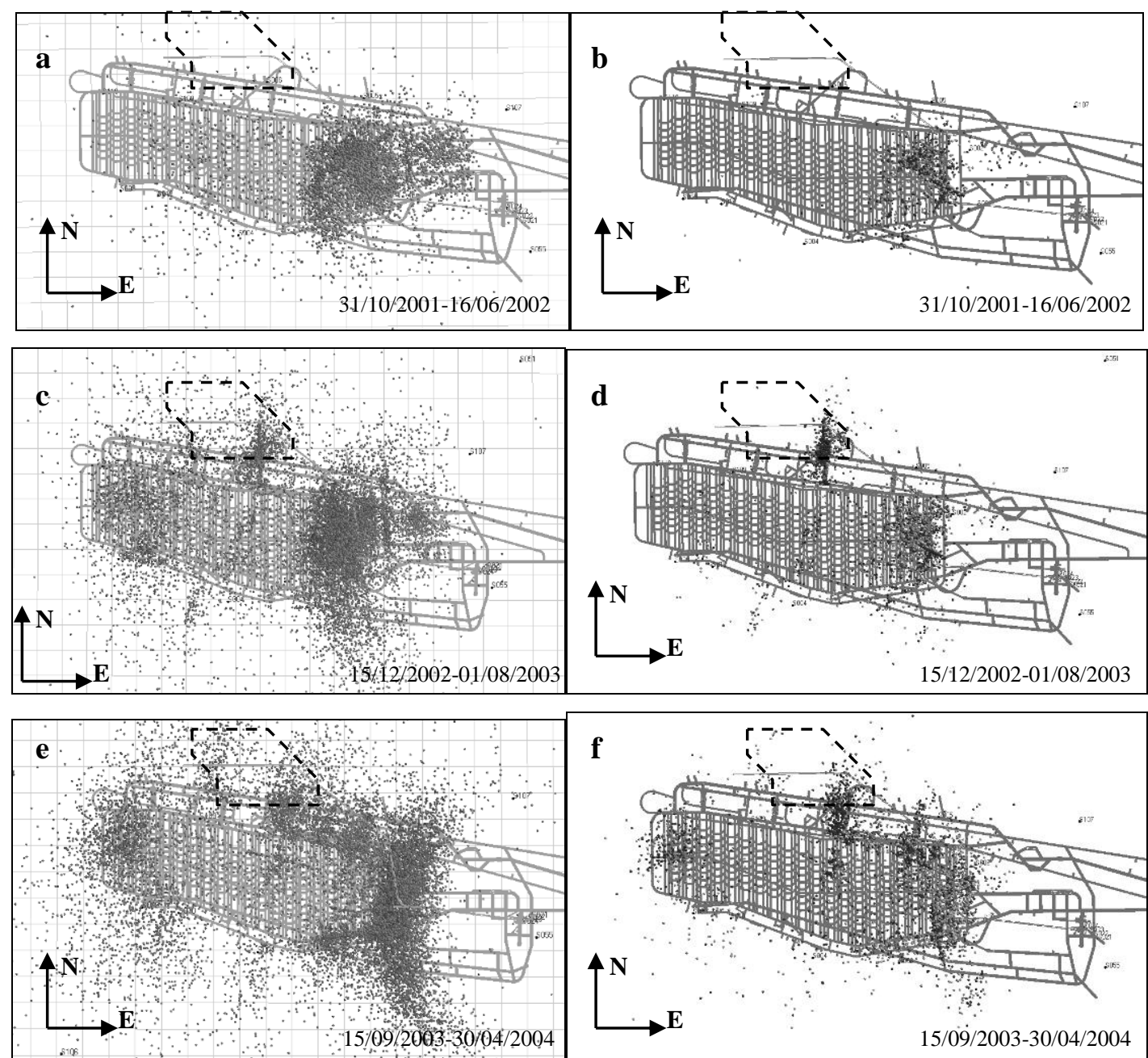

Figure 7 Plan view of the seismicity at Palabora Mine in different periods preceding the open pit north wall failure in November 2003 (a-d) and post-failure (e-f). Left column (a, c, e) shows all events scaled to moment magnitude, right column $(b, d, f)$ shows only events with $\mathrm{CI}>\mathrm{O}$ scaled to $\mathrm{CI}$. The dashed outline represents the projection of the open pit mobilised zone

Figure 9 shows the evolution of the internal structure in the seismic cluster located in the north and northeast sides of the low open pit, the region with seismic record closer to the area of the slope failure observed in November 2003. The stereographs represent the density of the poles fitted to all possible planes formed with every three events in the cluster (e.g. Reyes-Montes and Young, 2006). The maxima represent therefore, the normal to the dominant orientation of the planar structure underlying the seismic cluster. An interpretation of the maxima in the density plots is shown in the accompanying diagrams. The initial intervals, characterised by lower activity rate, show a dominant subvertical orientation, changing into dominant $\sim 60^{\circ}$ dipping planes. This orientation is subparallel to the free surface of the open pit. The development of a fracture structure with a dominant orientation subparallel to the free surface indicates the development of a zone of weakness that can trigger major failure. This orientation is observed in the four to five months period preceding the open pit failure, when activity rate also reaches its peak. 


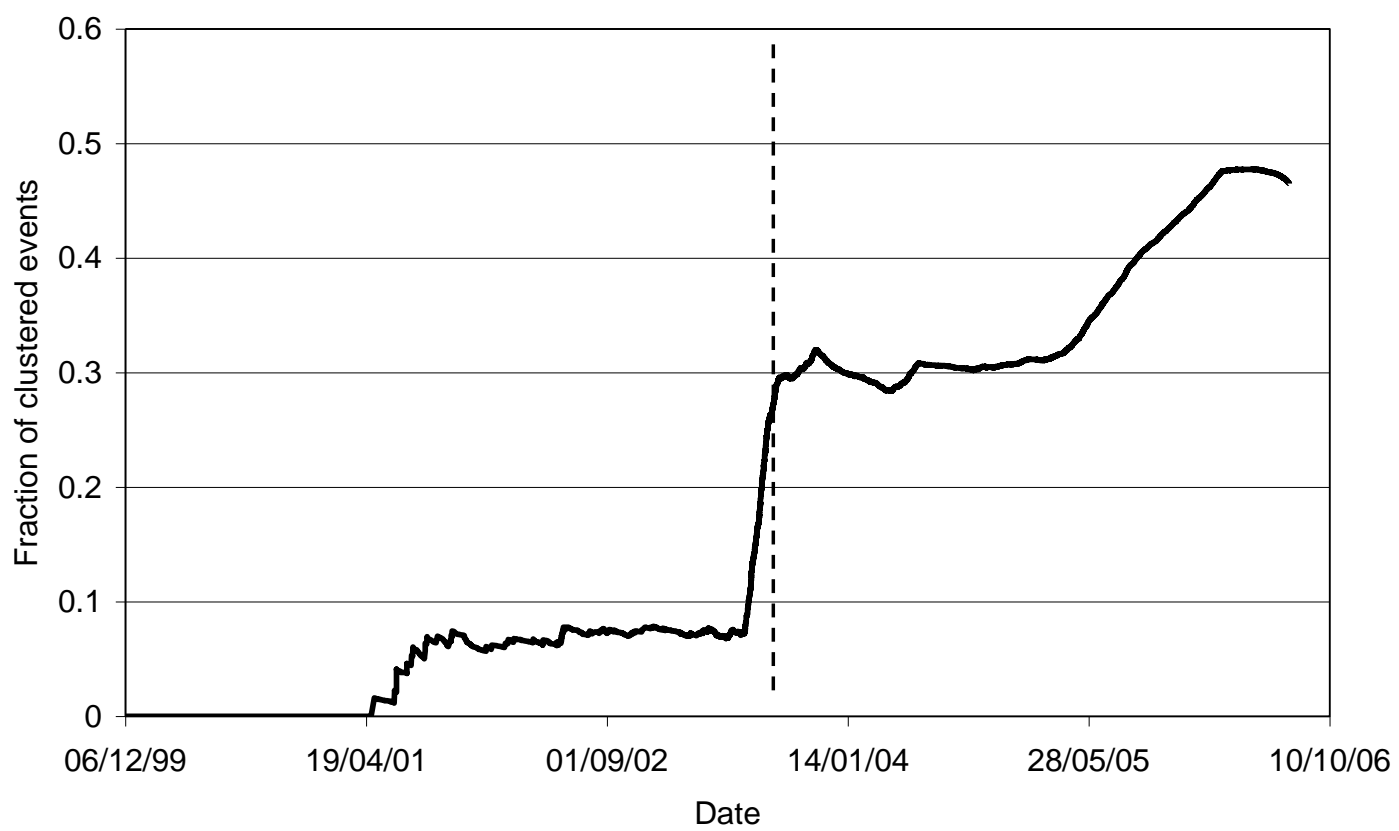

Figure 8 Evolution of the relative abundance of clustered events during the undercut and production of Palabora underground cave. The vertical dashed line marks the time of the slope failure in the open pit initiated at upper levels

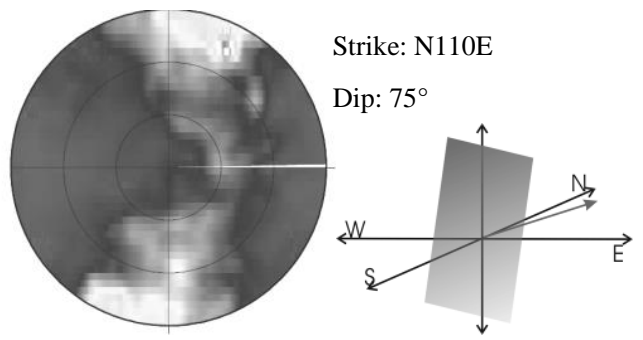

(a) $15 / 06 / 2000-22 / 10 / 2001$

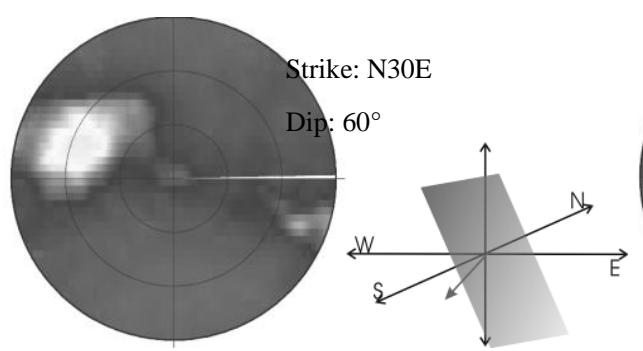

(c) $02 / 06 / 2003-28 / 07 / 2003$

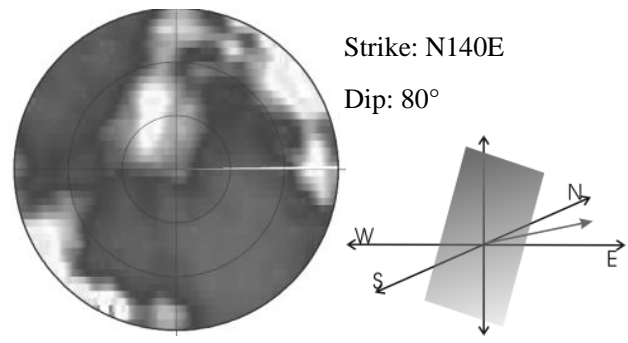

(b) $15 / 12 / 2002-30 / 12 / 2002$

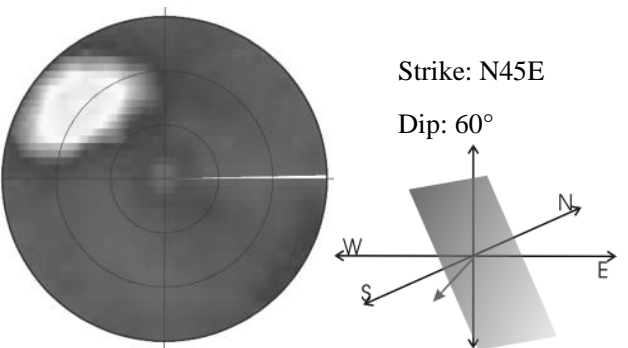

(d) $06 / 11 / 2003-19 / 03 / 2004$

Figure 9 Evolution of the structure within the seismic cloud located in the vicinity of the lower open pit. The diagrams show the interpretation of the peak density of poles observed in the sterographs

\subsection{Numerical simulation of seismicity}

The overall advance rate, thickness and spatial distribution of seismicity within a numerical model of caving can be determined by the empirically-derived criterion in Equation (6) (after Diederichs, 2000). This criterion is based on the back-analysis of seismic response in a number of deep Canadian operations and has 
been successfully applied in back-analyses of the recorded seismicity at Northparkes E26 Lift 2 cave (Pierce et al., 2007).

$$
\sigma_{1}=\sigma_{3}+\left[D_{\text {Thres }}\right] \times \text { UCS }
$$

The $\mathrm{D}_{\text {Thres }}$ value in Equation (6) represents the conditions in which acoustic emissions (scaled microseismicity) may be recorded in a laboratory rock sample associated with the initiation of new fractures and dilation of the sample. It has also been shown to correspond to the point at which measurable microseismicity might be recorded in a mine (Sainsbury et al., 2008). The value is generally between 0.3 and 0.42 .

Based on the results of large-scale $\left(128,000 \mathrm{~m}^{3}\right)$ synthetic rock mass (SRM) simulations conducted by Mas Ivars et al. (2008), $\mathrm{D}_{\text {Thres }}$ values for each of the rock mass domains at Palabora have been determined and are provided in Table 1. Validation of the SRM responses is described in Sainsbury et al. (2008) and has been conducted by using the MS techniques described herein, and matching the failure mechanism associated with the north slope failure along with the cave propagation rate.

Table 1 Damage threshold values determined from SRM modelling

\begin{tabular}{lllll}
\hline & Carbonatite & $\begin{array}{l}\text { Micaceous } \\
\text { Pyroxenite }\end{array}$ & Foskorite & Dolerite \\
\hline East-west direction & 0.3 & 0.35 & 0.5 & 0.2 \\
North-south direction & 0.45 & 0.45 & 0.5 & 0.2 \\
Vertical direction & 0.3 & 0.3 & 0.35 & 0.2 \\
\hline
\end{tabular}

For each of the rock mass domains, the $\mathrm{D}_{\text {Thres }}$ is presented in Figure 10 along with the Hoek-Brown failure envelopes.

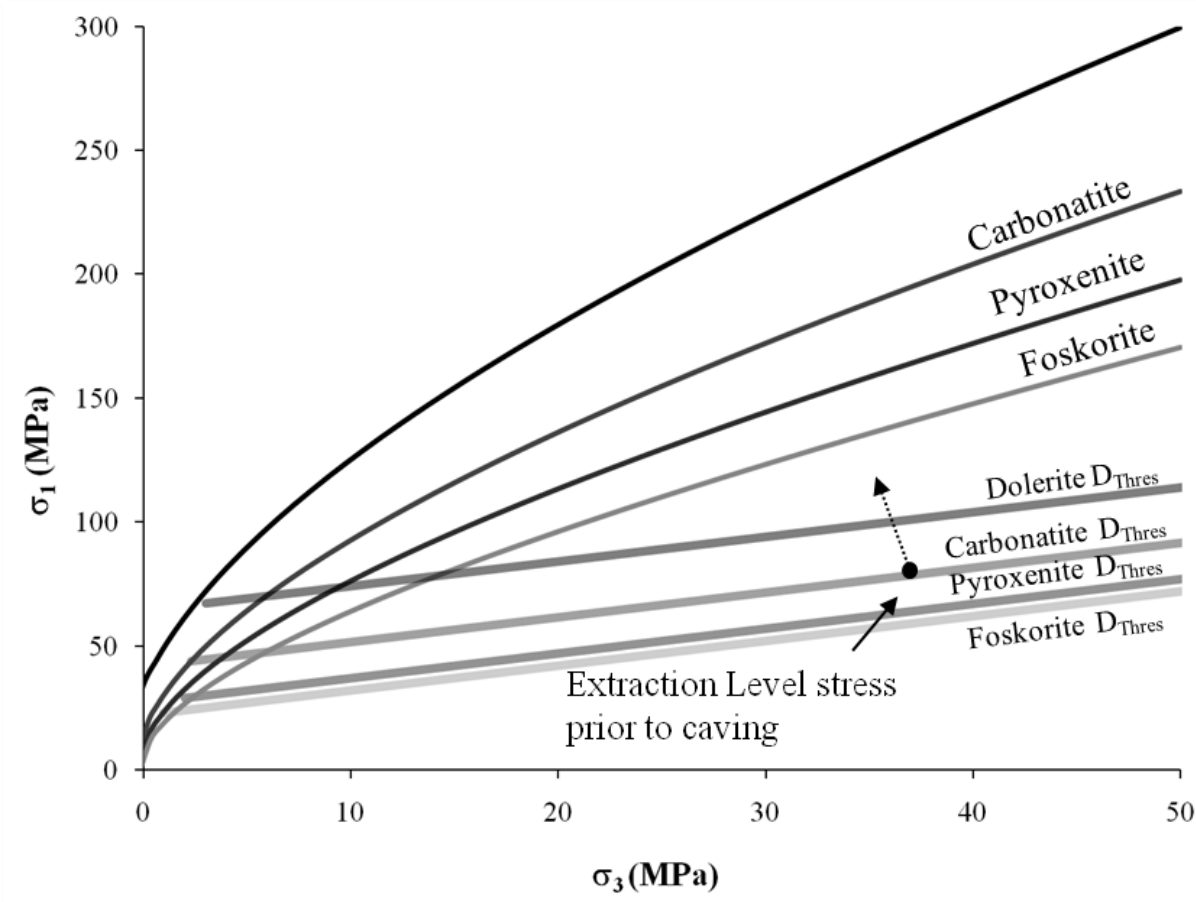

Figure 10 Average strength rock mass failure envelopes and minimum damage thresholds

The foskorite and pyroxenite units provide the lowest estimates of peak strengths, and have the lowest $\mathrm{D}_{\text {Thres }}$ (e.g. require lowest stress to induce irrecoverable plastic damage to the rock mass). It can be seen that the $\mathrm{D}_{\text {Thres }}$ for each of the foskorite and pyroxenite rock mass domains have been exceeded prior to caving. 
Using the SRM responses developed for each of the rock mass domains at Palabora (described in Mas Ivars et al., 2008), and simulating production from the cave by the methodology described in Sainsbury et al. (2008) seismicity around the advancing cave and north wall failure area has been assessed. The results are provided in Figure 11.

During the early stages of undercutting and production simulation (Figure 11(a)) the predicted seismicity is strongly correlated to the mining operations and follows the progression of the undercut. As production draw increases, and the hydraulic radius increases, a rapid advance of the seismogenic zone through crown pillar between the extraction level and base of the open pit is seen. Seismicity around the location of the north wall failure area immediately below the open pit is also observed (Figure 11(b)). At the time of the north wall failure, increased seismic activity around the failure zone is observed (Figure 11(c)). Existing conditions show a migration of seismicity to beneath the extraction level (Figure 11(d)). These observations made from the numerical model match with those determined from the seismic data, as discussed in Section 3.2.

It can be seen from Figure 12 that the north wall failure initiates and propagates in the pyroxenite and foskorite units - that exhibit the lowest peak strength and $\mathrm{D}_{\text {Thres }}$ as presented in Figure 10.
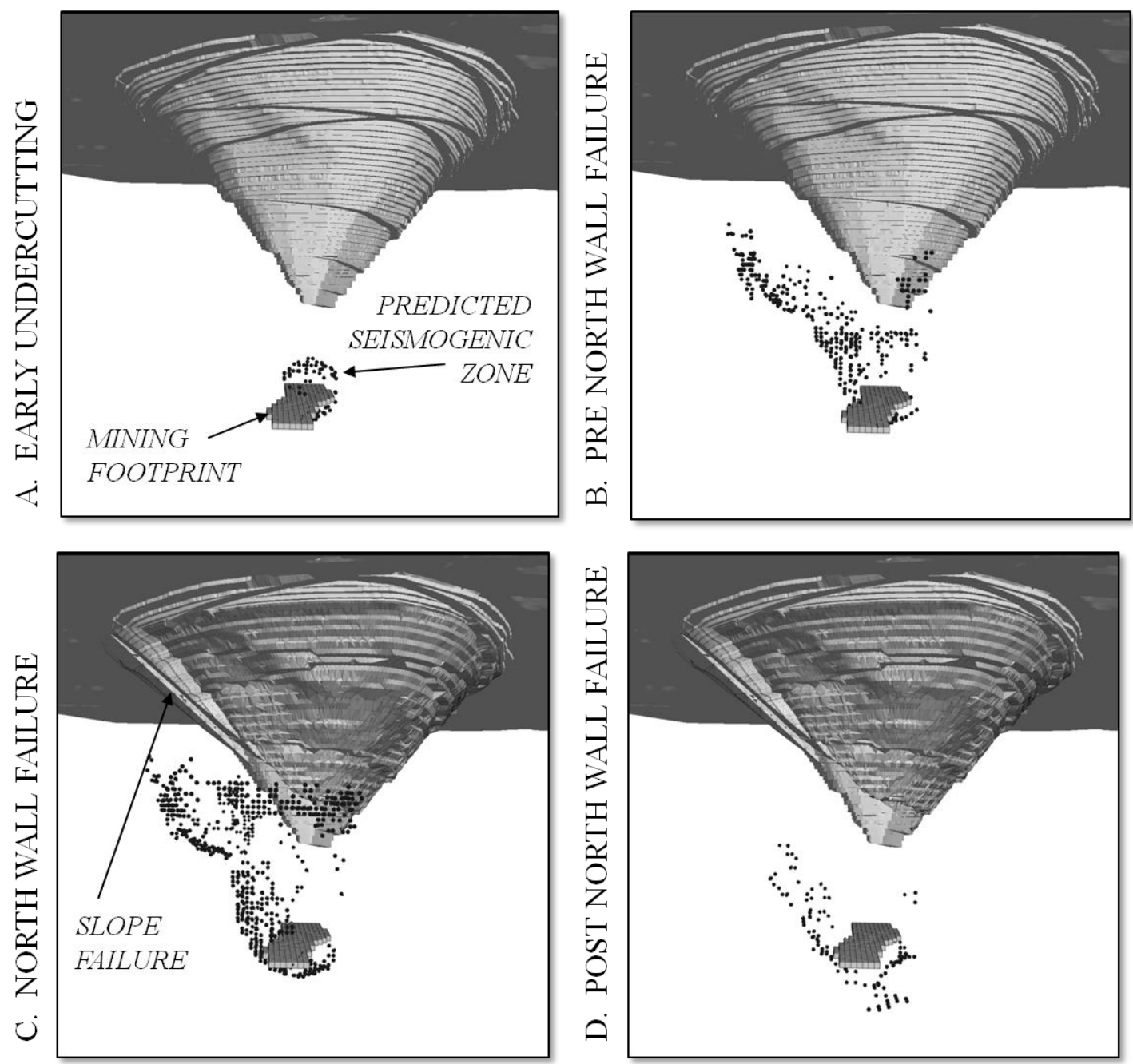

Figure 11 Predicted seismicity around the north wall failure during production simulation 


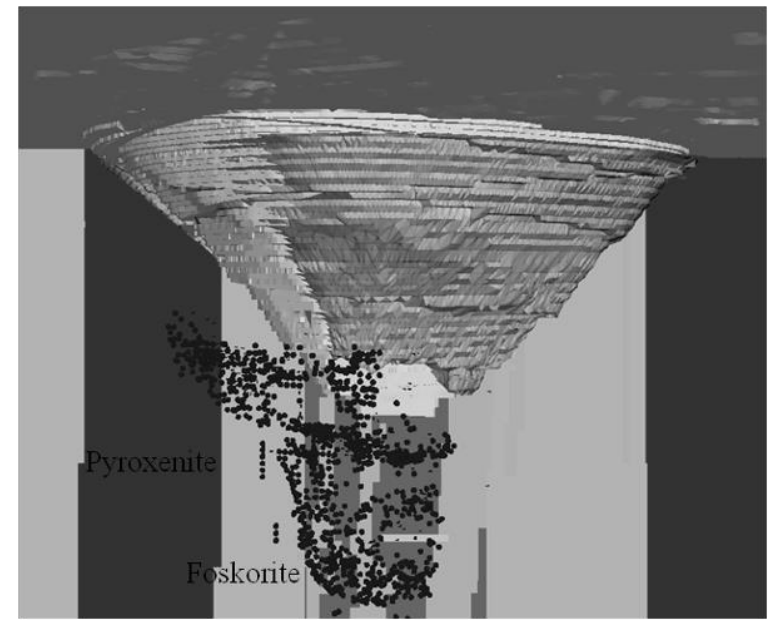

\section{Figure 12 Section looking east through north wall failure showing predicted seismicity around north wall failure and geomechanical domains}

\section{Conclusions}

A series of analyses of the microseismicity located in the cave and lower open pit provide a strong indication of the development of significant damage in the rock mass below the open pit's north slope in the months preceding its failure in November 2003. This failure was initiated $\sim 200 \mathrm{~m}$ above the monitored region. Observations of failure zones in three-dimensional numerical models describe very similar macro behaviour to that observed in situ. The increase in stresses induced by the underground processes caused an upward migration of the seismicity to the lower open pit.

First-order information is provided by the location and activity rate of the MS, which shows a peak of activity around the lower open pit in June 2003. The analysis of the b-value showed a relative minimum in the interval between May and November 2003. As with the seismic rate, the pattern in this lower region is believed to be ahead of the behaviour in the volume surrounding the higher failure zone.

The CI, a seismic damage parameter based on event separation and size, was used to study the interaction between events and the degree of damage induced in the underground cave. The results showed high damage accumulation in the volume located beneath the open pit's north wall during the months preceding the failure.

The analysis of the internal structure defined by the MS events in the cluster showed the definition of a well defined structure over the monitored period. This can be interpreted as the creation or reactivation of a zone of weakness. The initial trends show events defining marked subvertical fractures. The trend becomes shallower, evolving towards steep dipping fractures around June 2003, subparallel to the failure plane observed later in the north wall. This period is characterised by peak activity rates and high degrees of clustering, and precedes the observed slope failure of November 2003.

The combination of numerical cave analysis techniques and SRM technology with MS analysis techniques allows a preliminary assessment of potential volumes of rock failure during caving operations to be completed prior to production commencing, and these predictions to then be validated and further developed as the mining operations are performed and the rock's in situ behaviour observed.

\section{Acknowledgements}

The authors wish to acknowledge Rio Tinto and in particular Andre van As, and other the members of the MMT project for sponsoring the development of the seismic processing technologies. Thanks also go to Stefan Glazer for his help compiling the seismic data from Palabora mine. 


\section{References}

Diederichs, M.S. (2000) Instability of Hard Rockmasses: The Role of Tensile Damage and Relaxation, PhD Thesis, University of Waterloo, $617 \mathrm{p}$.

Falmagne, V. (2002) Quantification of rock mass degradation using microseismic monitoring and applications for mine design, PhD thesis, Queen's University, Kingston, Canada.

Gibowicz, S.J. and Kijko, A. (1994) An introduction to mining seismology, Academic Press.

Glazer, S.N. (2002-2006) Monthly Seismic Monitoring Reports, July 2002 to June 2006, Reports to Palabora Mining Company Limited.

Glazer, S.N. and Hepworth, N. (2003) Seismicity Induced by Cave Mining at Palabora Mining Company, Version 1.0, March 2003.

Glazer, S.N. and Hepworth, N. (2006) Crown pillar failure mechanism - case study based on seismic data from Palabora Mine, Mining Technology, Vol. 115, No. 2, pp. 75-84.

Hanks, T.C. and Wyss, N. (1972) Use of Body-Wave Spectra in Determination of Seismic - Source Parameters, Bulletin of the Seismological Society of America, Vol. 62(2), pp. 561-589.

Lockner, D.A., Moore, D.E. and Reches, Z. (1992) Microcrack interaction leading to shear fracture, in Proceedings 33rd U.S. Symposium on Rock Mechanics, J.R. Tillerson and W.R. Wawersik (eds), A.A. Balkema, Rotterdam, pp. 807-816.

Madariaga, R. (1976) Dynamics of an expanding circular fault, Bulletin of the Seismological Society of America, Vol. 66, No. 3, pp. 639-666.

Mas Ivars, D., Pierce, M., DeGagné, D. and Darcel, C. (2008) Anisotropy and scale dependency in jointed rock mass strength - A synthetic rock mass study, in Proceedings First International FLAC/DEM Symposium on Numerical Modelling (Continuum and Distinct Element Numerical Modeling in Geo-Engineering), R. Hart, C. Detournay and P. Cundall (eds), 25-27 August 2008, Minneapolis, USA, Minneapolis: Itasca, Paper No. 06-01.

Pettitt, W.S. and Young, R.P. (2007) InSite Seismic Processor, Technical Appendices to the Users Manual, Shrewsbury, UK, Applied Seismology Consultants Ltd.

Pierce, M., Cundall, P., Potyondy, D. and Mas Ivars, D. (2007) A Synthetic Rock Mass Model for Jointed Rock, in Rock Mechanics: Meeting Society's Challenges and Demands (1st Canada-U.S. Rock Mechanics Symposium), Vancouver, May 2007, E. Eberhardt, D. Stead and T. Morrison (eds), Taylor and Francis Group, London, Vol. 1: Fundamentals, New Technologies and New Ideas, pp. 341-349.

Reches, Z. and Lockner, D.A. (1994) Nucleation and Growth of Faults in Brittle Rocks, Journal of Geophysical Research-Solid Earth, Vol. 99(B9), pp. 18159-18173.

Reyes-Montes, J.M. and Young, R.P. (2006) Interpretation of fracture geometry from excavation induced microseismic events, in Proceedings International Symposium of the International Society for Rock Mechanics, Eurock 2006, 9-12 May 2006, Liege, Belgium.

Reyes-Montes, J.M., Pettitt, W.S., Haycox, J.R., Hemmings, B. and Young, R.P. (2009) Microseismic analysis for the quantification of crack interaction during hydraulic stimulation, SEG International Exposition and 79th Annual Meeting, 25-30 October 2009, Houston, Texas, USA.

Sainsbury, B., Pierce, M. and Mas Ivars, D. (2008) Analysis of Caving Behaviour Using a Synthetic Rock Mass Ubiquitous Joint Rock Mass Modelling Technique, in Proceedings 1st Southern Hemisphere International Rock Mechanics Symposium (SHIRMS), Y. Potvin, J. Carter, A. Dyskin and R. Jeffrey (eds), 16-19 September 2009, Perth, Australia, Australian Centre for Geomechanics, Vol. 1 - Mining and Civil, pp. 243-253.

Young, R.P., Collins, D.S., Hazzard, J., Reyes-Montes, J.M. and Baker, C. (2007) Quantifying and Interpreting Microseismicity, In Challenges in Deep and High Stress Mining, Y. Potvin, J. Hadjigeorgiou and D. Stacey (eds), Australian Centre for Geomechanics, Perth, pp. 469-476. 
